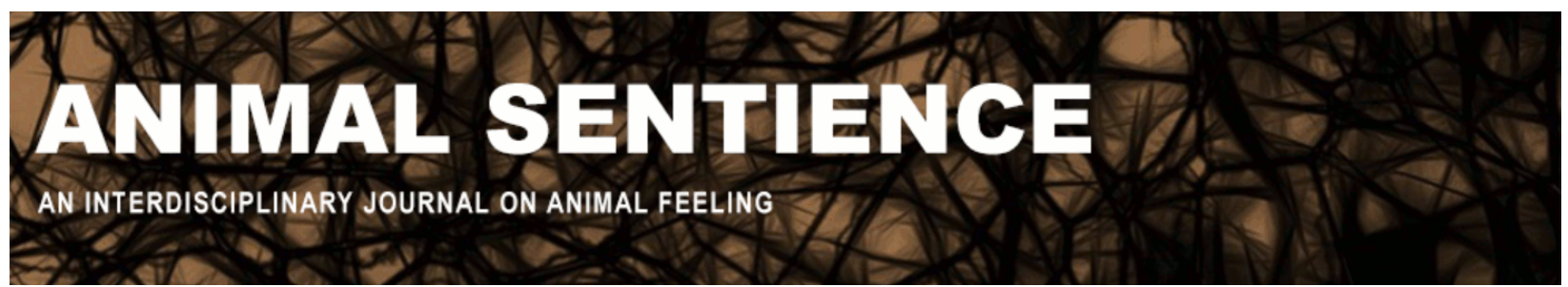

Vonk, Jennifer (2020) No room for speciesism in welfare considerations. Animal Sentience 29(5)

DOI: $10.51291 / 2377-7478.1586$

Date of submission: $2020-06-12$

Date of acceptance: 2020-06-15

(c)

This article has appeared in the journal Animal

Sentience, a peer-reviewed journal on animal

cognition and feeling. It has been made open access,

free for all, by WellBeing International and deposited

in the WBI Studies Repository. For more information,

please contact

wbisr-info@wellbeingintl.org.

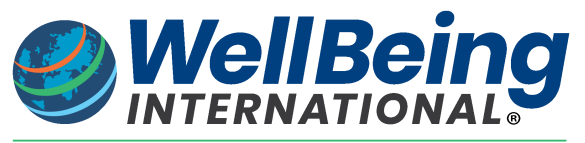

SOLUTIONS FOR PEOPLE, ANIMALS AND ENVIRONMENT 


\title{
No room for speciesism in welfare considerations
}

Commentary on Mikhalevich \& Powell on Invertebrate Minds

\author{
Jennifer Vonk \\ Department of Psychology, Oakland University
}

\begin{abstract}
Speciesism should play no role in determining welfare outcomes. Cognition may vary within species as well as between species, but broad classifications such as invertebrates are functionally meaningless in this context. Cognition should relate to welfare only to the extent that it relates to the capacity to suffer or to experience pleasure.
\end{abstract}

Jennifer Vonk, Professor of Psychology, Oakland University, Rochester, MI, has published over 100 articles, chapters and books in the area of animal and human cognition and development. Website

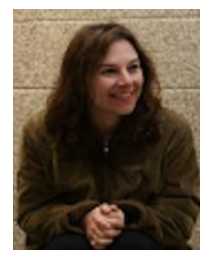

It is perfectly reasonable for Mikhalevich \& Powell (2020) (M\&P) to call for an end to the speciesism that permeates the field of animal welfare. There is no defensible reason to apply different welfare criteria to some living beings simply on the basis of their taxonomic classifications. This is particularly the case when the classification is extremely broad and functionally meaningless. The category of invertebrates covers more than $95 \%$ of all known species, including organisms as diverse as cephalopods and Drosophila. In the same way that the color of one's skin should not have any bearing on their ethical treatment, the presence or absence of a spine should not dictate the ethical treatment of nonhumans.

M\&P focus on the internal, cognitive lives of invertebrates, and seem to be arguing that evidence of complex cognition earns animals a higher priority for welfare considerations. They review an impressive body of research that indicates greater cognitive complexity in invertebrates than is generally attributed to them. Although this insight is valuable in challenging our perspectives on invertebrates, a focus on cognitive complexity is dangerous in its anthropocentrism. Humans value intellect because they believe it is what sets them apart and places them atop a hierarchy of evolutionary superiority (Chapman \& Huffman, 2018). But there is nothing about cognitive superiority that deserves greater consideration than, for example, physical strength, beauty, ecological purpose, and the list goes on.

Contrary to Levy's (2020) suggestion that M\&P should treat cognitive capacity as a direct factor for moral decisions, I would argue that cognition should be considered relevant to ethical treatment only insofar as it relates to particular types of suffering or pleasure that an organism can experience. This explicit role of cognition in predicting species' welfare should be highlighted rather than using the upper limits of cognition to justify improved treatment. I agree with Levy that the issue of consciousness is something of a red herring. This line of reasoning was prominent in the commentaries on Chapman \& Huffman (2018), which lobbied instead for a focus on the capacity to suffer (Shackelford, 2018; Vonk, 2019). Being aware of one's existence and capacity 
for death does allow for unique categories of suffering that are not applicable to most nonhumans. For example, when humans are aware that they will die at a young age, they lament the loss of their future and future missed opportunities (McMahan, 2002). Thus far, there is no evidence of this level of reflection on the part of any nonhuman. There is no evidence that nonhumans represent death as a permanent absence of both physical and conscious existence (Brosnan \& Vonk, 2019), thus eliminating a significant category of distress from their capacity for suffering in the threat of death. However, there are other aspects of cognition that we are probably unaware of that allow other species to suffer in ways that humans do not.

Although cognitive complexity is highly correlated with phylogenetic relatedness, this relationship is not isomorphic. There can be significant variability between species within taxa in their need for social interaction, space, varied diet and numerous other factors that influence welfare. Giant pandas can be provided with a single type of food (bamboo) while black bears and brown bears are generalists and require much greater variety and opportunity to search for and extract food. The link between cognition and welfare should be examined at an even finer level; the individual rather than the species level. Focusing on species membership alone neglects factors such as cognitive impairment and rearing history that affect individual responses to the same conditions. A feral dog that has never known human companionship may find human attention aversive and stressful whereas an abandoned pet is likely to be comforted by human attention (Willen et al., 2017).

I agree with M\&P that whether events are experienced as aversive or pleasurable is more important than assessing pain alone. The opportunity to thrive is beginning to be considered an important welfare consideration (Brando \& Buchanan-Smith, 2018). Distress, fear, boredom and many other states in addition to somatic pain are aversive too - and may be more likely to be experienced by more complex organisms. The direct link between cognition and psychological discomfort and pleasure should be explored more deeply before resting on evidence of cognitive complexity alone as justification for moral treatment.

Of secondary importance is the continued debate in comparative cognition about the extent to which animals are merely stimulus-response organisms blindly engaging in behavior without a sense of purpose or awareness versus the idea that animals are flexible and capable of abstract thought. Comparative psychologists are coming to recognize that this is a false dichotomy (Vonk \& Edge, in press). Furthermore, this kind of discourse is like a sand-trap; the harder you dig, the deeper you become buried in it.

M\&P set this problem aside, stating: "Because this problem applies to all of comparative cognition, we will not delve into it here." One problem with this dismissal is that they cite arguments from philosophers alone, neglecting the prominent arguments posed by comparative psychologists who are actually engaged on the front lines of this work. As M\&P point out, one can almost always provide simpler and simpler explanations for purportedly complex behavior, and this endless cycle detracts from the main key points in a discussion of welfare. However, understanding the precise cognitive mechanism underlying seemingly intelligent behavior can help determine an animal's needs for cognitive stimulation and choice. Comparative psychologists aim to do exactly this by using a better understanding of cognition to inform welfare (Clark, 2017).

The bottom line is that decisions about appropriate welfare for various species cannot be based on arbitrary features like the presence or absence of a spinal column or a particular brain structure. Humans with a limited understanding of different species' experiences and capacities 
must resist the inclination to label some species as more or less deserving than others. Welfare considerations should be linked to the capacity to experience various forms of adversity and pleasurable experiences. The way that cognition is linked to these capacities is bound to be far more complex than any taxonomic distinction would indicate, but M\&P bring us closer to understanding how the world is perceived through the senses of invertebrates.

\section{References}

Brando, S., \& Buchanan-Smith, H. (2018). The 24/7 approach to promoting optimal welfare for captive wild animals. Behavioural Processes, 156, 83-95.

Brosnan, S. F. \& Vonk, J. (2019). Nonhuman primate responses to death. In T. K. Shackelford \& V. Zeigler-Hill (Eds.), Evolutionary perspectives on death (pp. 77-107). Springer, New York, NY.

Chapman, C. A., \& Huffman, M. A. (2018). Why do we want to think humans are different? Animal Sentience 23(1).

Clark, F. E. (2017). Cognitive enrichment and welfare: Current approaches and future directions. Animal Behavior and Cognition, 4(1), 52-71.

Levy, N. (2020). It might not matter very much whether insects are conscious. Animal Sentience 29(2).

McMahan, J. (2002). The ethics of killing: Problems at the margins of life. Oxford University Press.

Mikhalevich, I., \& Powell, R. (2020). Minds without spines: Evolutionarily inclusive animal ethics. Animal Sentience 29(1).

Shackelford, T. K. (2018). Can they suffer? Animal Sentience 23(4).

Vonk, J. (2019). Unique in degree not kindness. Animal Sentience 23(21).

Vonk, J., \& Edge, J. (in press). False dichotomies in the study of animal cognition. In S. Della Sala (Ed.), Encyclopedia of behavioural neuroscience ( $2^{\text {nd }}$ ed.). Elsevier.

Willen, R. M., Mutwill, A., MacDonald, L. J., Schiml, P. A., \& Hennessy, M. B. (2017). Factors determining the effects of human interaction on the cortisol levels of shelter dogs. Applied Animal Behaviour Science, 186, 41-48. 


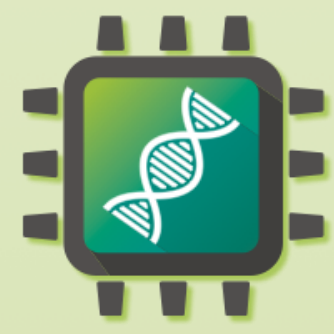

\section{Summer School 2020} INNOVATIVE SCIENCE WITHOUT ANIMALS

\section{June 22-26, 2020}

\section{Online Virtual Conference}

Calling all students and early-career researchers!

Join us for a FREE conference on innovative approaches in toxicology and biomedical sciences!

\section{This event features:}

- Lecture sessions about modern alternatives to the use of animals in toxicology and biomedical sciences

Virtual laboratory tours

E-poster presentations

Virtual engagement with speakers and attendees

Deadline to apply for the full program is June 10. Registration for individual lectures is available.

For more information visit InnovativeScience2020.org

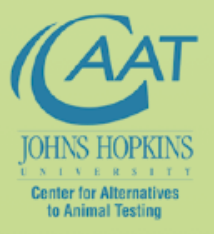

Physicians

Com

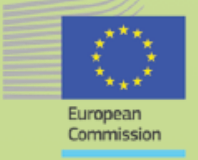

